\title{
APTOS AOS TRABALHOS BRAÇAIS, SUSCETÍVEIS AOS VÍCIOS MORAIS: REPRESENTAÇÕES DO HOMEM NEGRO NA REVISTA EDUCAÇÃO PHYSICA (1939-1944)
}

\author{
SUITABLE FOR MANUAL LABOR; SUSCEPTIBLE TO THE MORAL VICES: \\ REPRESENTATIONS OF BLACK MEN IN THE JOURNAL EDUCAÇÃO PHYSICA \\ (1939-1944)
}
APTOS A LOS TRABAJOS MANUALES, SUSCEPTIBLES A LOS VICIOS MORALES: REPRESENTACIONES DEL HOMBRE NEGRO EN LA REVISTA EDUCAÇÃO PHYSICA (1939 - 1944)

\author{
Jéferson Luis Staudt*, André Luiz dos Santos Silva*, Magna Lima Magalhães*
}

Palavras chave:

Sexismo.

Grupo com

ancestrais do continente africano. Publicações periódicas.

Keywords:

Sexism.

Group with African

ancestry.

Journals.

Palabras clave:

Sexismo.

Grupo de

ascendencia

continental africana.

Publicaciones

periódicas
Resumo: A partir dos marcadores de gênero e raça, este texto analisa as representações do homem negro na revista Educação Physica entre 1939 e 1944, período em que Francisco de Assis Hollanda Loyola ficou no cargo de editor técnico do periódico. Para tanto, as edições compreendidas entre os números 34 e 81 foram acessadas e analisadas, com base nos pressupostos teórico-metodológicos da História Cultural. Em um período em que raça, povo e nação eram entendidos quase como sinônimos, a revista Educação Physica veiculou representações que tornam os homens negros visiveis por seus dotes físicos e suas fragilidades morais. "Naturalmente" propensos aos vícios e às tarefas braçais, as representações dos homens negros são produzidas na negação de suas características étnico-raciais, enfatizando, como efeito, os predicados provenientes dos corpos brancos.

Abstract: Based on gender and race markers, this text analyzes representations of black men in the magazine Educação Physica between 1939 and 1944, when Francisco de Assis Hollanda Loyola was its technical editor. Issues 34-81 were analyzed under the theoretical/methodological assumptions of Cultural History. In a period in which race, people, and nation were understood almost as synonyms, Educação Physica conveyed representations that portrayed black men according to their physical strengths and their moral weaknesses. "Naturally" prone to addiction and manual labor, black men's depictions denied their racial/ethnic characteristics, emphasizing white bodies' attributes as their effect.

Resumen: A partir de los marcadores de género y raza, este texto analiza las representaciones del hombre negro en la revista brasileña Educação Physica, de 1939 a 1944, periodo en que Francisco de Assis Hollanda Loyola ocupó el cargo de editor técnico del periódico. Para ello, las ediciones emprendidas entre los números 34 y 81 fueron accedidas y analizadas a partir de los presupuestos teórico/metodológico de la Historia Cultural. En un periodo en que raza, pueblo y nación eran comprendidos casi como sinónimos, la revista brasileña Educación Physica vehiculó representaciones que tornan los hombres negros visibles por sus dotes físicos y sus debilidades morales. "Naturalmente" propensos a los vicios y a las tareas manuales que requieren esfuerzo físico, las representaciones de los hombres negros son producidas en la negación de sus características étnico-racial, enfatizando como efecto los predicados provenientes de los cuerpos blancos...
* Universidade Feevale. Novo Hamburgo, RS, Brasil. E-mail: jefersonstaudt@feevale.br andrels@feevale.br; magna@feevale.br

Recebido em: 31-05-2017 Aprovado em: 24-04-2018

DOI: http://dx.doi.org/10.22456/1982-8918.73848 (c) (1) (2) Licence 


\section{INTRODUÇÃO}

A partir dos marcadores de gênero e raça, este texto analisa as representações do homem negro na revista Educação Physica entre 1939 e 1944', período em que Francisco de Assis Hollanda Loyola ficou no cargo da editoração técnica do periódico (SCHNEIDER, FERREIRA NETO 2004). Mestre de Campo da Milícia, Loyola foi filiado à Ação Integralista Brasileira (AIB $)^{2}$, movimento político de inspiração fascista que defendia homogeneidade racial e identidade nacional como elementos fundamentais para seu projeto (SIMÕES; GOELLNER; 2012; SENTINELO, 2010).

Cabe destacar que a Ação Integralista Brasileira sofre uma série de reformulações em decorrência da instauração do Estado Novo $(1937-1945)^{3}$, que, sob o argumento de defesa nacional, dissolve o Congresso, implementa uma nova constituição e extingue os partidos políticos. Assim, a AIB transforma-se na "Associação Brasileira de Cultura" (ABC), cujas funções se mantiveram até 1938. Neste contexto, "desvinculado" das entidades políticas às quais pertencia, Loyola assume a editoração técnica da Educação Physica e produz uma política editorial que evidencia o homem negro, valendo-se de representações que interseccionam gênero e raça. Inspirado nos princípios provenientes da $\mathrm{AIB}$ e, em alguma medida, em enunciados racistas que circulavam no período do Estado Novo (1937-1945), Loyola esteve envolvido com a divulgação, via Educação Physica, de entendimentos consensuais sobre as masculinidades negras, que, por sua suposta "naturalidade", tornam improváveis questionamentos sobre 0 caráter plural da identidade dos "homens de cor" (LOURO, 2008).

Fundamentado na História Cultural (CHARTIER, 2002) e nos Estudos Culturais (HALL, 1997), esta análise dialoga com as fontes, concebendo-as como forma de representação, o que torna os achados abertos à atribuição de sentidos. Entendidas como mecanismos de significação que produzem discursos, por guardarem visões de mundo, as representações constituem "realidades" sociais e constroem identidades de gênero e étnico-raciais. Com efeito, essas representações geram um processo de convencimento de que "as realidades" e os grupos são justamente da forma como são exibidos/produzidos na revista.

Tal qual um "currículo", a revista Educação Physica ${ }^{4}$ reitera as intenções políticas, morais, sociais e pedagógicas de sua periodização $0^{5}$ a cada nova edição. Essa característica do periódico é apresentada nas páginas iniciais de cada publicação, endereçada a professores, técnicos e diretores. Assim, em uma leitura "preliminar", parece que a revista tem como finalidade promover, de uma maneira "envolvente" e "autorizada", a adesão dos leitores aos conceitos pedagogizados por ela.

\footnotetext{
1 De veiculação no Brasil datada entre os anos de 1932 e 1945, a revista Educação Physica foi um dos primeiros periódicos especializado na área. Sua periodicidade e produtividade foram consideravelmente ampliadas justamente no período entre 1939 e 1944, quando Hollanda Loyola era seu Editor Técnico.

2 Criada por Plínio Salgado em 7 de outubro de 1932, a AIB, adotava um modelo de organização que seguia um conjunto doutrinário de rituais e normas: obrigatoriedade do vestuário - camisas verdes e gravatas pretas -, saudação com o braço direito estendido, bradando a palavra de origem tupi-guarani "anauê", e o uso da letra grega sigma (口) como símbolo (FAGUNDES, 2012).

3 De modo geral, a Era Vargas é dividida em três fases: 1) Governo Provisório, de 1930 a 1934; 2) Governo Constitucional, de1934 a 1937; 3 ) Estado Novo, de 1937 a 1945. O Estado Novo, em especial, configura-se no período político de Vargas marcado por características ditatoriais (PANDOLFI, 1999)

4 Sob o nome de "Educação Física", a revista publica na página 80, da edição 37, os assuntos que congrega, bem como indica a que público suas publicações se destinam.

5 Ao lado do sumário de cada edição, a revista apresenta os seguintes escopos: "Vulgarizar os princípios científicos e básicos da educação física; estimular a prática dos esportes como fator de aperfeiçoamento da raça; incentivar a formação de técnicos especialistas; propagar os fins morais e sociais das atividades físicas; despertar a atenção pública para êsse aspecto do problema educativo; coadjuvar o govêrno e instituições particulares na execução de seus programas de educação física" (REVISTA EDUCAÇÃO PHYSICA, ed. 54, 1941, p.1).
} 
No entanto, assim como a imprensa periódica das primeiras décadas do século $X X$, a revista Educação Physica foi produzida como veículo de divulgação de interesses políticos, perpassada por projetos sociais e por concepções de raça (CHARTIER, 2002; LUCA, 2005). Ao considerar que o endereçamento e o escopo da revista fazem parte de uma política editorial, esta análise lança olhares sobre os textos e imagens localizados às margens das "evidências". Assim, este texto argumenta que o periódico acolhe e produz representações que condizem com a cultura de racismo notabilizada no Brasil daquele momento. Assim, apesar do debate raciológico ter se constituído numa complexa e divergente rede de exercícios de poder, a revista em questão parece estar muito mais afeita às formulações biodeterministas de raça (SILVA, 2014) e a concepções que davam a ver os corpos negros como inferiores ${ }^{6}$.

Neste sentido, a investigação privilegiou o período de Editoração Técnica de Hollanda Loyola, que compreende as edições de setembro de 1939 a julho de 1944․ A busca por imagens e textos relevantes para a análise das representações de masculinidade e raça revelou algumas seções que se tornaram especialmente profícuas: "Diversos", "Doutrina”, "Educação Física", "Informações Úteis", "Pugilismo", "Box" e "Esgrima". De modo mais específico, essas seções abrigam os seguintes artigos: "Muitos boxeadores negros terminam tragicamente"; "O Box conselho aos pugilistas" e "A tragédia dos grandes boxeadores", publicações substanciais para o processo de escrita do presente texto.

\section{MASCULINIDADE, RACISMO E BIODETERMINISMO NA POLÍTICA EDITORIAL DA REVISTA EDUCAÇÃO PHYSICA}

Na década de 1930, a Educação esteve alinhada às pretensões do Estado nacional para o Brasil. A positivação do trabalho e da identidade do trabalhador, bem como a homogeneidade étnico-cultural, foram questões substanciais à campanha de nacionalização que via na Educação, na Educação Física e na imprensa correlata espaços de divulgação de seu projeto de nação (CUNHA, 1999). De dimensões políticas e culturais, o programa de nacionalização estado-novista esteve calcado na construção da nacionalidade e na valorização da brasilidade. O empreendimento político pretendia evidenciar, demarcar e positivar os elementos culturais e biológicos supostamente próprios da identidade nacional brasileira, conferindo coesão e homogeneidade à Nação (BOMENY, 1999; CARNEIRO, 2013).

Assim, a definição do tipo racial brasileiro era uma questão que concentrava a atenção da elite política, intelectual e da imprensa brasileira nas primeiras décadas do século XX e, em especial, na década de 1930. Mesmo com o predomínio do ideário de "democracia racial brasileira", e com o empreendimento varguista de valorização das heranças negras na década de $1930^{\circ}$, as práticas voltadas à imigração demonstravam a preocupação política com a homogeneidade étnico-racial nacional, legada do século XIX. Sendo a imigração europeia pensada como estratégia de branqueamento, a redução das taxas imigratórias europeias nos

\footnotetext{
6 Não existia consenso intelectual e político no que tange ao debate racial presente na época. Em paralelo à vulgarização de "saberes" racistas, eugênicos e neolombrosianos, difundia-se a realização de eventos contrários às premissas do racismo científico, caso dos Congressos AfroBrasileiros e dos movimentos de resistência negra, em especial, a Frente Negra Brasileira (FNB) (SILVA, 2014; SILVA, 2010; SKOLAUDE, 2014; DOMINGUES, 2013)

7 A coleção completa da revista Educação Physica encontra-se disponível para acesso no acervo histórico da Biblioteca Edgard Sperb da Escola de Educação Física, Fisioterapia e Dança da Universidade Federal do Rio Grande do Sul. Números da mesma revista também estão disponíveis no CEMEF (Centro de Memórias da Educação Física) da Universidade Federal de Minas Gerais.

8 Partiu do então ministro da educação, Gustavo Capanema, ao médico Arthur Ramos, a solicitação para encaminhar os festejos do cinquentenário da Abolição da Escravatura, promovido pelo Governo Vargas em maio de 1938. Os festejos articulados por Ramos incluíram seminários, lançamento de livros, apresentações de canto, dentre outras intervenções (CUNHA, 1999).
} 
anos 30 tornou-a uma questão de segurança nacional ${ }^{9}$ (CARNEIRO, 2013; MAGALHÃES, 2017; SEYFERTH, 1999).

Inspirado no racismo e na xenofobia dos regimes nazista e fascista, médicos, eugenistas, políticos e intelectuais da vanguarda brasileira, dentre os quais Oliveira Viana ${ }^{10}$ e Renato Ferraz Kehl' ${ }^{11}$, foram acionados para pensar uma política imigratória para o país. Com 0 intuito de salvaguardar a identidade étnico-racial nacional, foram implementadas medidas restritivas que favoreciam 0 ingresso de imigrantes brancos ${ }^{12}$, preferencialmente católicos, ocidentais e produtivos, e barravam a entrada no país de pessoas de cor negra e amarela ${ }^{13}$ (CARNEIRO, 2013; SILVA, 2008). Içados à condição de excêntricos por seus supostos "desvios" atitudinais, subversividades e inferioridade étnico-racial, os negros tiveram sua imagem associada à desordem, ao demoníaco e ao animalesco. Nessa perspectiva, as barreiras restritivas à imigração, a veiculação de uma literatura racista, bem como os artefatos da imprensa, constituíam a opinião pública favorável à exclusão de determinados grupos étnico-raciais e políticos (CARNEIRO, 2013).

Como parte da imprensa periódica da década de 1930, a revista Educação Physica, no que tange aos aspectos étnico-raciais, destinou um modesto espaço de visibilidade aos negros, nas suas publicações. Em geral, os "homens de cor" estiveram vinculados às práticas esportivas, especialmente do futebol, do boxe, do atletismo e em algumas publicações foram evidenciados como "objetos" de estudos sobre a constituição racial do povo brasileiro. A exemplo disso, na seção denominada "Informações Uteis/Secção de Consultas"14", Loyola classifica os grupos raciais no país, ao responder a pergunta de uma leitora acerca da existência de alguma classificação racial no Brasil. A resposta de Loyola, publicada na revista, baseiase nas classificações de Roquette-Pinto ${ }^{15}$, e distribui os grupos raciais da seguinte maneira: "1ํ leucodermos ou brancos, $2^{\circ}$ faiodermos ou mulatos (branco x negro), $3^{\circ}$ xantodermos ou caboclo (branco x índio) e 4ํㅡㄹ melanodermos ou negro" (LOYOLA, 1939, p. 62).

Sob esse ângulo, mesmo que Roquette-Pinto refutasse a existência de hierarquias entre os "tipos brasilianos", defendia que cada tipo racial possuía características comportamentais e psicológicas congênitas. Os resultados de suas pesquisas acabaram reiterando noções comuns à época, tais como a concepção de que o perfil dos mestiços (faiodermos) tinha características emotivas e afetivas à parte dos atributos de intelecto e civilidade (SOUZA, 2011). 0 antropólogo concluiu em seus estudos, com base na genética mendeliana, que os mestiços tendiam ao branqueamento, uma vez que nos cruzamentos inter-raciais sobressairiam os caracteres antropológicos dos "brancos brasilianos", por serem elementos hereditários dominantes. Nesse

\footnotetext{
9 Além de pessoas negras, outros grupos também foram constituídos naquele momento como elementos nocivos à campanha de nacionalização do país, caso dos ciganos, comunistas, judeus, prostitutas, vagabundos, russos, assírios, dentre outros (CARNEIRO, 2013).

10 Advogado e historiador, Oliveira Viana foi um dos maiores entusiastas do branqueamento da população, sustentando a ideia de que 0 negro era "incivilizável" (MAGALHÃES, 2017).

11 Médico eugenista muito influente no Brasil, Renato Kehl advogava entre anos de 1910 e 1920 que as práticas de exercitação física eram capazes de eugenizar a população do país. Além disso, via a miscigenação como algo pernicioso, pois, segundo ele, o negro era um elemento biologicamente inferior em relação ao branco (SILVA, 2014).

12 De qualquer modo, por intermédio da educação, esses imigrantes deveriam ser incorporados à cultura nacional e distanciados de seus vínculos de origem - costumes, religião e língua -, possibilitando a construção de laços de pertencimento e identificação com os elementos próprios da identidade brasileira enaltecidos naquele período (CARNEIRO, 2013; SEYFERTH, 1999).

13 Tais medidas restritivas são observadas nos parágrafos $6^{\circ}$ e $7^{\circ}$ do art. 121 da Constituição de 1934. Além disso, outros tantos grupos foram constituídos naquele momento como elementos nocivos a campanha de nacionalização do país, caso dos ciganos, comunistas, judeus, prostitutas, vagabundos, russos, assírios, dentre outros (CARNEIRO, 2013)

14 Espaço reservado à solução de dúvidas sobre a Educação Física. Revista Educação Physica, Rio de Janeiro, 1939. 
caso, Roquette-Pinto alinhava-se aos intelectuais e cientistas que viam no branqueamento uma possibilidade auspiciosa de pensar o futuro racial da Nação. Tendo em vista as questões estéticas, ainda argumentava que negros e mestiços eram fisicamente mais feios que sujeitos caucasianos (SOUZA, 2011).

Cabe destacar que, naquele momento, a política do branqueamento dava sustentação à ideia de "democracia racial" e permitia negar o racismo brasileiro simultaneamente à paulatina exclusão desse grupo, via cruzamentos inter-raciais. Ou seja, buscava-se disseminar a ideia de que os negros eram incluídos pela miscigenação, ao passo que eram excluídos pelo branqueamento. Portanto, a mestiçagem e a educação como estratégia de nacionalização tornaram-se balizas de uma biopolítica do Estado, que construiu, a partir de regimes de verdade, representações sobre raça, miscigenação e Nação (SILVA; 2015; SPECHT, SILVA, 2014).

Ainda que a mistura racial brasileira fosse um legado que supostamente resultaria em um grande entrave para o ingresso do Brasil no conjunto das nações ditas civilizadas, os escritos de Gilberto Freyre em Casa Grande e Senzala (1933) revestiram de conotações positivas a miscigenação e deram suporte para a construção da noção de "democracia racial" no país (ANDREWS, 1997; MAGALHÃES, 2017).

A miscigenação foi um dispositivo capaz de acomodar "raças distintas" e gerar coesão entre distintos elementos que constituíam a Nação, produzindo um conjunto de saberes a respeito da identidade nacional e do nacionalismo, subjetivando sujeitos e construindo modos de se referir ao país, a partir de uma discursividade elementar (SPECHT; SILVA, 2014; TADEI, 2002). Além disso, a suposta rejeição aos postulados do racismo científico e a aparente inexistência de discriminação racial no país, manifestadas através da ideia de "democracia racial brasileira", tornaria o Brasil do pós 1930 moralmente superior a países como Estados Unidos e Alemanha, marcados por intensa repressão às minorias étnico-raciais (MAGALHÃES, 2017).

Em meio à complexidade da questão racial do período Vargas, Holanda Loyolla publica em 1941, na edição número 61 da revista Educação Physica, o artigo "Os Jangadeiros Cearenses". Nesse texto, o autor apresenta quatro conterrâneos jangadeiros negros que, em um ato descrito como sendo de admirável bravura, lançaram-se aos mares do Ceará. Mesmo tripulando uma jangada dita primitiva, venceram todas as adversidades do oceano para então chegarem às terras cariocas. Assim narrou Loyola:

Toda a Nação vibrou com esse arrojo; a cidade engalanou-se para receber os valorosos jangadeiros; o povo delirou em aclamações calorosas; nada lhes foi poupado em festas, em homenagens, em distinções. Eu os aplaudi com entusiasmo e os abracei comovidos; encantou-me a simplicidade de sua modéstia a humildade de suas atitudes. Músculos enegrecidos pelo trabalho, peles crestadas pelo sol implacável dos trópicos, corpos a transpirar força e resistência, olhos a expressar coragem e lealdade, humildes de gestos e parcimoniosos de palavras, sem uma referência às dificuldades que enfrentaram, como se tivessem feito a cousa mais natural deste mundo, eles, os jangadeiros, são bem a expressão do nosso querido Ceará, angustiado e heroico, lutador e bravo, dedicado e bom. Neles eu vi, como em síntese, toda a grandeza da história épica desse grande povo. [...] Jangadeiros humildes, meus heroicos patrícios, eu vos saúdo e dou o meu viva ao Ceará pela glória do nosso muito amado e querido Brasil (LOYOLA, 1941, p. 9).

Ao descrever os "jangadeiros cearenses" como sujeitos heroicos, bravos, leais, humildes, corajosos e detentores de uma história épica, o autor simultaneamente afirmou sua própria 
identidade. Ao se referir ao Ceará e conferir ao estado reconhecimento e valorização, concedeu uma identidade positiva para os indivíduos e para a coletividade cearense, inclusive para si próprio. No entanto, apesar de Loyola apresentar como extraordinário o feito de seus conterrâneos, na imagem intitulada "Educação Física visita os Jangadeiros" esses homens sequer foram nomeados. Identificados como "os quatro jangadeiros", esses sujeitos eram os únicos negros presentes na fotografia e as únicas pessoas que não tiveram seus nomes divulgados.

Ao partilhar elementos identitários com os "quatro jangadeiros", Hollanda Loyola, homem cearense, atribui valor à própria identidade nordestina e o faz, entretanto, rejeitando e indefinindo os "outros cearenses", homens negros. Na posição privilegiada de quem anuncia "a diferença", Hollanda Loyola, ao mesmo tempo em que enaltece as qualidades físicas de resistência, vigor e força, constituintes de masculinidades louváveis, desqualifica os "jangadeiros" ao apresentálos como sujeitos "sem nome" e destituídos de história. Nesse jogo de representações, "os jangadeiros" conferem coerência e estabilidade à identidade étnico-racial de Loyola, ao mesmo tempo em que reiteram o entendimento do homem negro como sujeito apto às atividades braçais (FERREIRA; CAMARGO, 2011).

Localizados fora da "norma" (LOURO, 2008), seria presumível que os homens negros não receberiam maiores menções. Na medida em que os homens negros se encontravam distanciados da centralidade do modelo étnico-racial pretendido por parte significativa da elite política e intelectual da época, e evidenciados nas representações masculinas eugênicas e eurocêntricas, o artifício pedagógico de não nomear a presença negra na revista confere coesão e segurança ao sujeito localizado no "centro". Representação semelhante a essa pode ser observada também no artigo "O Box: Conselhos aos pugilistas", texto traduzido do francês por A.F. Lobato (1941). No referido texto, o autor discorre sobre os aspectos técnicos dos golpes e movimentos oriundos do boxe, indicando que o jab havia sido um movimento vulgarizado, na França, por um atleta negro. Apesar de destacado atleta, o boxeador também não é nomeado, assim como outras menções acerca de sua identidade foram invisibilizadas.

A revista Educação Physica, ao optar pela indeterminação e, em especial, pela glorificação e enaltecimento dos homens negros por sua "extraordinária capacidade física", acolhe e reitera representações correntes que notabilizam os negros como hábeis trabalhadores braçais (FERREIRA; CAMARGO, 2011). Assim, veicula representações naturalizadas do homem negro, que articula a um só tempo concepções de masculinidade e raça: violência e força física. Com efeito, em sua edição nำ 71, a revista Educação Physica publica o artigo "Muitos boxeadores negros morrem tragicamente", escrito por John Lardner. O autor inicia seu texto fazendo menção a Joe Louis, atleta negro norte-americano que, segundo ele, deveria ficar atento às fatalidades que haviam acometido outros tantos boxeadores de sua raça. Lardner continua sua narrativa, afirmando que:

Bastam poucos exemplos, o caso do grande Joe Gans. Este melancólico negro de Baltimore, cuja fisionomia o poeta Joaquim Miller descreveu como sendo 'uma máscara trágica' [...]. Quando o pobre negro foi declarado tuberculoso e os seus máus orientadores o abandonaram, Gans, trabalhando por sua conta, poz fóra de combate a meia dúzia dos que antes o 'haviam vencido' [...] o mal ia minando seu organismo e nunca o favoreceu a imparcialidade dos brancos [...]. Quando morreu em consequência da tuberculose, Gans tinha uns trinta e quatro anos [...]. Outro caso é o de Sam Langford [...] quiçá, o melhor boxeador que houve na história [...]. Isso não impediu [que] nos últimos anos de sua atuação engordasse até parecer um barril, em virtude de seu treinamento à base de cerveja e maças. Um dos 
seus olhos foi atacado de catarata e Langford perdeu outro em consequência dos golpes recebidos em sua peleja com Fred Fulton [...]. O serviço de beneficência da municipalidade de Nova York Ihe dá um auxílio de 2.55 dolares por semana e Ihe pega 0 aluguel do quarto [...] Joe Walcott [...] sofreria de artério-esclerose, asma, psicose-senil... e fome [...] acusado de abusar do álcool [...]. Outro caso mais: o senegalês Batting Siki. Quando este aborígine do Senegal se instalou em Nova York, já haviam passado seus melhores dias [...] costumava passear pelo bairro novayorkino, chamado de [...] Hell's Kitchen, dando bofetadas nos guardas, encrencando com os motoristas, quebrando os móveis das tabernas e endividando-se até não poder [...]. Acompanhava-o por toda a parte um senegalês, cuja missão consistia em carregar um garrafão de vinho, que o amo bebia no meio da rua. Na noite antes de pelejar contra Kid Norfolk bebeu uma caixa de cerveja [...] não faltou quem the desse balaços e desta vez Siki não levantou do sangue, em meio de sargeta [...]. E outro mais. Jack Johnson, o campeão mundial de todos os pesos [...]. Depois de ter posto fóra várias fortunas, Johnson está se exibindo em um circo de Coney Island [...] por 10 cêntimos a entrada. Pouco antes o fazia em um circo de 'pulgas amestradas', salão de tiro ao alvo e 'galeria de fenômenos' situada na parte mais sórdida da rua Quarenta-e-Dois (LARDNER, 1942, p. 18-19).

Na edição n-73, a revista torna a fazer referência a Joe Louis no artigo "A tragédia dos grandes boxeadores: Joe Louis às portas da falência". Mesmo que o texto tenha representado o boxeador norte-americano como o melhor pugilista de todos os tempos, não hesitou em desqualificar a carreira do atleta que dentro dos "rings" manipulava bem o seu corpo, mas que, fora dele, não tinha a mesma capacidade para administrar a fortuna conquistada como lutador. É interessante observar que John Lardner (1942) não se encarregou somente de relatar o término precoce e problemático daqueles boxeadores negros, ao afirmar que Joe Louis deveria ficar atento àquelas possibilidades, ele de algum modo essencializou todos os boxeadores negros como naturalmente inclinados aos mesmos fins.

Ao tornar Joe Louis um provável delinquente, alcoólatra, imoral, agressivo, doente e psicótico, tal qual os demais atletas negros, pelas mãos de Lardner (1942), o "currículo" da revista constrói um perfil característico à raça durante o período de editoração técnica de Hollanda Loyola. Nesse aspecto, a revista acomoda "saberes" biotipológicos, eugênicos e neolombrosianos, ventilados na época por autores como Afrânio Peixoto ${ }^{16}$, Leonídio Ribeiro ${ }^{17}$ e Waldemar Berardineli, que em seus estudos advogavam a delinquência, o alcoolismo e as anomalias como atributos próprios da "natureza" de homens negros e mestiços. Cabe ressaltar que Leonídio Ribeiro e Waldemar Berardineli receberam em janeiro de 1935, em Turim, o prêmio Cesare Lombroso ${ }^{18}$, por uma pesquisa realizada com 33 negros/mestiços "homicidas, alcoólatras e vadios" e 195 indivíduos com traços degenerativos. Os resultados da pesquisa evidenciaram, entre negros e mestiços, sinais de "criminalidade étnica manifesta na "natureza" de seus corpos (CUNHA, 1999; SILVA, 2014; SKOLAUDE, 2014).

Ao manifestar "os perigos da biologia negra" ao corpo espécie da Nação (FOUCAULT, 2005), a revista Educação Physica acomoda concepções que contribuem para identificar

\footnotetext{
160 médico e escritor Afrânio Peixoto fez parte do movimento higienista nas primeiras décadas do século XX, no Rio de Janeiro, e, ao longo da década de 1930, seus estudos passaram a contemplar o debate criminológico ligado à antropologia criminal lombrosiana (CUNHA, 1999). 17 Leonídio Ribeiro esteve à frente das primeiras pesquisas realizadas pelo Laboratório de Antropologia Criminal, que reuniu médicoslegistas, clínicos especializados em endocrinologia e "antropologistas". A equipe encabeçada por Ribeiro deu inicio às primeiras investigações biotipológicas destinadas à identificação criminal do país em 1932 (SILVA, 2014).

18 O criminalista Cesare Lombroso (1835-1909) dedicou seus estudos à análise da delinquência e suas possíveis manifestações no corpo dos criminosos. Assim, defendia que era possível identificar marcas ou "desvios" nos corpos que fossem tendenciosos ao delito. Em 1870 , Lombroso realiza a autópsia do cadáver do criminoso Giuseppe Villella e percebe que, no interior do crânio do assassino, há uma cavidade comum em outras espécies de animais de níveis inferiores de evolução. Sendo assim, depreende que a delinquência carregaria marcas de animalidade (GALERA, 2007; FERLA, 2009 apud SILVA, 2014).
} 
os negros como elementos "nocivos" à formação da identidade étnico-racial brasileira. Para tanto, veicula representações que incitam a produção de uma identidade negra hostilizada, patológica, viciosa e degenerada. Entretanto, apesar dos esforços empreendidos em pesquisas no campo da antropologia criminal, alinhadas com as teorias neolombrosianas, outros modos de significação da população negra também se faziam presentes. A esse respeito, vale apontar a realização dos Congressos Afro-Brasileiros, no Recife, em 1934, e em Salvador, em $1937^{19}$, que abrigaram perspectivas contrárias às políticas racistas hegemônicas da época e problematizaram os pressupostos teórico-metodológicos do racismo científico. Os congressos propuseram uma reestruturação no campo analítico dos estudos africanos/afro-brasileiros e das relações étnico-raciais com a substituição da noção biológica de "raça" pelo conceito de cultura, com a intenção de justificar as diferenças raciais não como dados naturais, mas, sim, como fatos socialmente construídos ${ }^{20}$ (SILVA, 2010).

A década de 1930 ainda testemunhou a emergência da Frente Negra Brasileira (FNB), fundada em 1931, em São Paulo. O movimento emerge e aquece o debate sobre a necessidade de romper com as representações que desqualificavam e marginalizavam negras e negros brasileiros (DOMINGUES, 2007; DOMINGUES, 2013). Nesse sentido, em um contexto nacional que presentifica iniciativas políticas e intelectuais de resistência a pressupostos epistemológicos do racismo científico, a revista Educação Physica acomoda "saberes" biodeterministas sobre "raça" e partilha, na década de 1930, de concepções correntes que inferiorizavam os corpos negros. Além disso, estes pressupostos biológicos condizem com a linha editorial de Loyola, uma vez que, segundo Silva (2014), o debate biotipológico e as menções à eugenia são substancialmente ampliados durante seu período de direção técnica.

\section{CONSIDERAÇÕES FINAIS}

Tomada como inscrição e registro de projetos de sociedade, a revista Educação Physica constituiu-se como locus de produção de sentidos, manifestando pretensões nacionalistas e projetos de produção de uma identidade étnico-racial ao longo dos anos 1930 e 1940.

Em um período no qual esteve em curso um programa de nacionalização que deu ênfase especial à Educação e à Educação Física como forma de efetivar ideais raciais, o "currículo" da revista Educação Physica veiculou representações que reiteram os corpos negros como "desviantes", "perigosos", "imorais", "desordeiros" e "inferiores". Assim, ao tornar os homens negros visíveis por seus dotes físicos e suas fragilidades morais, a revista os representa como "naturalmente" propensos aos vícios e às tarefas braçais, contribuindo, deste modo, para a demarcação destes sujeitos como elementos indesejáveis e estranhos à pretendida identidade étnico-racial brasileira.

Entretanto, considerando a população negra como uma presença concreta na formação étnico-racial do país, foi necessário definir os lugares de visibilidade desse grupo em

19 O sociólogo Gilberto Freyre, sob assistência de seu primo, o professor e psiquiatra Ulysses Pernambuco, organizou o $1^{\circ}=$ Congresso Afro-Brasileiro (1ํ CAB) no Teatro Santa Isabel, entre os dias 11 e 16 de novembro, de 1934, na cidade do Recife/PE. O 2ํㅡㄹ Congresso AfroBrasileiro ( $2^{\circ} \mathrm{CAB}$ ) ocorreu em 1937 e foi realizado entre os dias 11 e 20 de janeiro, no Instituto Nina Rodrigues e no Instituto Geográfico e Histórico da Bahia (IGHB) (SILVA, 2010; SKOLAUDE, 2014).

20 Entretanto, o caráter positivo da influência africana e afro-brasileira no país não foi um total consenso entre as teses apresentadas nos congressos. Ainda que os eventos tenham oportunizado espaços de discussão crítica sobre as concepções hegemônicas do racismo científico, algumas teses apresentadas fundamentaram suas análises em aspectos biológicos, eugênicos e biotipológicos de degeneração racial de negros e mestiços, caso do Estudo Biotypologico de Negros e Mulatos Delinquentes, de autoria de Leonídio Ribeiro e Waldemar Berardinelli (SKOLAUDE, 2014). 
uma suposta sociabilidade que, por estimar a "democracia racial", deveria incluí-lo, mas sem perder de vista a necessidade de impor limites de aceitabilidade à incorporação desse grupo na coletividade.

Ainda que, na década de 1930, organizações negras e grupos de intelectuais defendessem abertamente representações positivas acerca da cultura e da raça negra, tais movimentos não teriam encontrado ressonância nas páginas da Educação Physica. Eventos como os Congressos Afro-Brasileiros, bem como ações provenientes do movimento "frentenegrino", não se fizeram presentes nas páginas do periódico, que teria acolhido, em contrapartida, debates oriundos de teorias biodeterministas e racistas como a eugenia e biotipologia.

Durante a direção técnica de Hollanda Loyola, o periódico constituiu a identidade dos homens negros como excêntrica, aquela que não poderia ser representada como dotada de predicados morais e intelectuais. Sua "semipresença" foi suficiente para reiterá-los como os "outros", "sem nome", "sem identidade", cujos "desvios" de sua "natural" condição imoral e subversiva precisariam ser evidenciados para negá-los como possibilidade étnica e estética em uma política editorial que desejava legar "aperfeiçoamento racial", robustez e beleza para as gerações futuras.

\section{REFERÊNCIAS}

ANDREWS, George Reid. Democracia racial brasileira 1900-1990: um contraponto americano. Estudos avançados, v. 11, n. 30, p. 95-115, 1997.

BOMENY, Helena. Três decretos e um ministério: a propósito da educação no Estado Novo. In: PANDOLFI, Dulce (Org). Repensando o Estado Novo. Rio de Janeiro: Fundação Getulio Vargas, 1999. p.137-166.

O BOX: conselho aos pugilistas. Educação Physica, Rio de Janeiro, n. 50, p. 42-45. 1941.

CARNEIRO, Maria Luiza Tucci. Racismo e Imigração: o modelo ideal do homem trabalhador no campo e na cidade (1930-1945). In: PASATTI, Matteo. Tra due crisi Urbanizzazione, mutamenti sociali e cultura di massa tra gli anni Trenta e gli anni Settanta. Bolonha: ArchetipoLibri, 2013. p. 111-140.

CHARTIER, Roger. A história cultural: entre práticas e representações. 2. ed. Lisboa: Difel, 2002.

CUNHA, Olívia Maria Gomes da. Sua alma em sua palma: identificando a "raça" e inventando a nação. In: PANDOLFI, Dulce (Org). Repensando o Estado Novo. Rio de Janeiro: Ed. Fundação Getulio Vargas, 1999. p. 257-288.

DOMINGUES, Petrônio. Movimento negro brasileiro: alguns apontamentos históricos. Revista Tempo, v. 12, n. 23, p. 100-122, 2007.

DOMINGUES, Petrônio. Como se fosse bumerangue: Frente Negra Brasileira no circuito transatlântico. Revista Brasileira de Ciências Sociais, v. 28, n. 81, p. 155-170, 2013.

EDUCAÇÃO Física. Educação Physica, Rio de Janeiro, n. 37, p. 80. 1940. 
EDUCAÇÃO PHYSICA, Rio de Janeiro, n. 54, 1941, p.1.

FAGUNDES, Pedro Ernesto. Morte e memória: a necrofilia política da Ação Integralista Brasileira (AIB). Varia História, v. 28, n. 48, p. 889-909, 2012.

FERREIRA, Ricardo Franklin; CAMARGO, Amilton Carlos. As relações cotidianas e a construção da identidade negra. Psicologia: Ciência e Profissão, v.31, n.2, p.374-389, 2011.

FOUCAULT, Michel. Em Defesa da Sociedade: curso no Collège de France (1975-1976). São Paulo: Martins Fontes, 2005.

HALL, Stuart. Representation: cultural representations and signifying practices. Londres, Sage/ The Open University, 1997.

LARDNER, John. Muitos boxeadores negros terminam tragicamente. Educação Physica, Rio de Janeiro, n. 71, p. 18-19, 1942.

LOURO, Guacira Lopes. Um corpo estranho: ensaios sobre sexualidade e teoria queer. Belo Horizonte: Autêntica, 2008.

LOYOLA, Hollanda. Seção de consultas. Educação Physica, Rio de Janeiro, n. 34, p. 62. 1939.

LOYOLA, Hollanda. Os jangadeiros cearenses. Educação Physica, Rio de Janeiro, n. 61, p. 9. 1941.

LUCA, Tânia Regina. História dos, nos e por meio dos periódicos. In: PINSKY, Carla Bassanezi (Org). Fontes históricas. São Paulo: Contexto, 2005. p. 111-153.

MAGALHÃES, Magna Lima. Associativismo Negro no Rio Grande do Sul. São Leopoldo: Trajetos, 2017.

SCHNEIDER, Omar; NETO, Amarílio Ferreira. Estratégias editoriais, enciclopedismo, produtos e publicidade na revista Educação Physica (1932-1945). Movimento, v. 10, n. 3, p. 23-52, 2004.

SENTINELO, Jaqueline Tondato. O lugar das raças no projeto de nação da Ação Integralista Brasileira. Revista Espaço Acadêmico, v. 9, n. 108, p. 145-152, 2010.

SEYFERTH, Giralda. Os imigrantes e campanha de nacionalização do Estado Novo. In: PANDOLFI, Dulce (Org). Repensando o Estado Novo. Rio de Janeiro: Ed. Fundação Getulio Vargas, 1999. p.199-228.

SILVA, André Luiz dos Santos. A perfeição expressa na carne: a educação física no projeto eugênico de Renato Kehl-1917 a 1929. 2008. 141f. Dissertação (Mestrado) - Programa de Pósgraduação em Ciências do Movimento Humano, UFRGS, Porto Alegre, 2008.

SILVA, André Luiz dos Santos. Nos domínios do corpo e da espécie: eugenia e biotipologia na constituição disciplinar da educação física. Porto Alegre: Orquestra, 2014.

SILVA, Mozart. Biopolítica, Narrativas Identitárias e Educação no Brasil (1900-1945). Revista Brasileira de História \& Ciências Sociais, v. 7, n. 14, p. 246-266, 2015.

SILVA, Sarah. Africanos e afro-descendentes nas origens do Brasil: raça e relações raciais no II Congresso Afro-Brasileiro de Salvador (1937) e no III Congresso Sul-Riograndense de História e Geografia do IHGRS (1940). 2010. 275f. Dissertação (Mestrado) - Curso de História, Programa de Pós-Graduação em História, UFRGS, 2010. 
SIMÕES, Renata; GOELLNER, Silvana. Educação Física e esportes na Ação Integralista Brasileira: Hollanda Loyola e a educação do corpo, Revista Brasileira de Educação Física e Esporte, v. 26, n. 2, p. 263-272, 2012.

SKOLAUDE, Mateus Silva. Identidade nacional e historicidade: $01^{\circ}$ Congresso Afro-Brasileiro de 1934. In: XII ENCONTRO ESTADUAL DE HISTÓRIA DA ANPUH-RS: História, verdade e ética, 12, 2014. Anais..., São Leopoldo: Unisinos, 2014. p. 1-16. Disponível em: <http://www. eeh2014.anpuh-rs.org.br/resources/anais/30/1404752235 ARQUIVO Texto-MateusSilvaSkolaude. pdf>. Acesso em: 18 maio 2018.

SOUZA, Vanderlei Sebastião de. Em busca do Brasil: Edgard Roquette-Pinto e o retrato antropológico brasileiro (1905-1935). 2011. 382f. Tese (Doutorado) - Programa de PósGraduação em História das Ciências e da Saúde da Casa de Oswaldo Cruz, Fiocruz, 2011.

SPECHT, Roberta; SILVA, Mozart. Canto orfeônico, democracia racial e biopolítica na era Vargas (1930-1945). Revista Jovens Pesquisadores, v. 4, n. 2, p. 108-117, 2014.

TADEI, Emanuel. A mestiçagem enquanto um dispositivo de poder e a constituição de nossa identidade nacional. Psicologia: Ciência e Profissão, v. 22, n. 4, p. 2-13, 2002.

A TRAGÉDIA dos grandes boxeadores: Joe Louis às portas da falência. Educação Physica, Rio de Janeiro, n. 73, p. 27 - 28. 1943. 


\section{Apoio financeiro:}

